\title{
Impact of Multiple Hygienic Interventions on Caregivers' Behaviors in a Conflict Setting, Yemen: Cluster-Randomized Controlled Trial
}

\author{
Mansour Al-Taj ${ }^{1}, \mathrm{PhD}$; Abdulawed Al Serouri ${ }^{2}$, Prof Dr \\ ${ }^{1}$ Department of Community Medicine, Sana'a University, Sana'a, Yemen \\ ${ }^{2}$ Field Epidemiology Training Program, Ministry of Public Health and Population, Sana'a, Yemen
}

\section{Corresponding Author:}

Mansour Al-Taj, PhD

Department of Community Medicine

Sana'a University

Modbah

Sana'a, 00967

Yemen

Phone: 9671375535

Email: mansouraltaj@yahoo.com

\section{Abstract}

Background: Several household hygiene programs have been implemented by the Ministry of Public Health and Population and international nongovernment organizations to reduce the risk factors related to child morbidity and mortality in Yemen. However, no research has been conducted to assess the impact of such interventions on caregivers' hygiene behavior. We therefore carried out a cluster-randomized controlled trial to assess whether such interventions could improve caregivers' hygiene behavior.

Objective: The study aims to identify the impact of hygiene promotion interventions on mothers' practices related to water, sanitation, and hygiene.

Methods: A 6-month cluster-randomized controlled trial was conducted in Hufash District of Al-Mahweet Province in Yemen from May to October 2015. In total, 20 villages were randomly selected and assigned to an intervention arm that received hygiene promotional interventions and a control arm. In total, 358 households were interviewed at baseline and the endpoint. A logistic regression model was fitted to data, and the adjusted odds ratio (AOR) was used to estimate the effect size of the intervention.

Results: The intervention made significant improvements in caregivers' handwashing after using a latrine (AOR 2.6, 95\% CI 1.75-3.90) and before feeding the baby (AOR 1.8, 95\% CI 1.14-2.92), safe disposal of child feces (AOR 2.0, 95\% CI 1.35-2.53), covering of remaining food (AOR 1.1, 95\% CI 1.08-1.19), cleaning of cooking utensils (AOR 1.27, 95\% CI 1.08-1.51), and cleanness of drinking water storage containers (AOR 1.3, 95\% CI 1.17-1.46). However, the intervention had no effect on caregivers' handwashing practices after cleaning child feces, before preparing food, and before eating a meal, as well as no improvement in cleanness of the floor of the kitchen.

Conclusions: The findings from this trial reveal the important role that hygiene promotion can play in improving caregivers' behaviors that could lead to better child health in high-risk communities where access to primary health care is limited.

Trial Registration: ClinicalTrials.gov NCT03810430; https://clinicaltrials.gov/show/NCT03810430

(iproc 2022;8(1):e36624) doi: 10.2196/36624

\section{KEYWORDS}

hygiene; intervention; Yemen 
Edited by Y Khader; this is a non-peer-reviewed article. Submitted 19.01.22; accepted 19.01.22; published 07.02.22.

Please cite as:

Al-Taj M, Al Serouri A

Impact of Multiple Hygienic Interventions on Caregivers'Behaviors in a Conflict Setting, Yemen: Cluster-Randomized Controlled Trial

iproc 2022;8(1):e36624

URL: https://www.iproc.org/2022/1/e36624

doi: $10.2196 / 36624$

PMID:

CMansour Al-Taj, Abdulawed Al Serouri. Originally published in Iproceedings (https://www.iproc.org), 07.02.2022. This is an open-access article distributed under the terms of the Creative Commons Attribution License (https://creativecommons.org/licenses/by/4.0/), which permits unrestricted use, distribution, and reproduction in any medium, provided the original work, first published in Iproceedings, is properly cited. The complete bibliographic information, a link to the original publication on https://www.iproc.org/, as well as this copyright and license information must be included. 